Brazilian Journal of Microbiology (2010) 41: 477-485

ISSN 1517-8382

\title{
CONSTRUCTION OF KILLER INDUSTRIAL YEAST SACCHAROMYCES CEREVISIAE HAU-1 AND ITS FERMENTATION PERFORMANCE
}

\author{
Bijender K. Bajaj ${ }^{*}$; S. Sharma ${ }^{2}$
}

${ }^{1}$ Department of Biotechnology, University of Jammu, Jammu-186 001, India; ${ }^{2}$ Department of Microbiology, CCS Haryana Agric. University, Hisar-125 004, India.

Submitted: October 17, 2008; Returned to authors for corrections: April 10, 2009; Approved: November 08, 2009.

\begin{abstract}
Saccharomyces cerevisiae HAU-1, a time tested industrial yeast possesses most of the desirable fermentation characteristics like fast growth and fermentation rate, osmotolerance, high ethanol tolerance, ability to ferment molasses, and to ferment at elevated temperatures etc. However, this yeast was found to be sensitive against the killer strains of Saccharomyces cerevisiae. In the present study, killer trait was introduced into Saccharomyces cerevisiae HAU-1 by protoplast fusion with Saccharomyces cerevisiae MTCC 475, a killer strain. The resultant fusants were characterized for desirable fermentation characteristics. All the technologically important characteristics of distillery yeast Saccharomyces cerevisiae HAU-1 were retained in the fusants, and in addition the killer trait was also introduced into them. Further, the killer activity was found to be stably maintained during hostile conditions of ethanol fermentations in dextrose or molasses, and even during biomass recycling.
\end{abstract}

Key words: killer yeast, distillery yeast, Saccharomyces cerevisiae, molasses, ethanol fermentation.

\section{INTRODUCTION}

Bio-ethanol, ethanol produced by fermentation of sugars, starchy or cellulosic hydolysate by yeast Saccharomyces cerevisiae or bacterium Zymomonas mobilis, has emerged as the most promising energy resource of future, in view of the rapidly dwindling world's fossil fuel reserves $(13,33)$. Besides, there is huge demand of ethanol as chemical feedstock and as a component of alcoholic beverages. In India and in most of the world, ethanol production is carried out by conventional batch fermentation under hostile environmental conditions without a precise control over various process parameters (31). Fermentation is generally run in open vessels and contamination by undesired wild yeast flora is quite common which often results in sluggish or stuck fermentation leading to lower ethanol yields. Among the several causes reported for sluggish or stuck fermentation, one potential cause may be contamination by the wild killer yeast which may not only compete with the starter culture for the substrate but also destroys it if the latter is sensitive to the toxin produced by the wild killer yeast, resulting in almost complete fermentation failure (2).

The killer phenomenon, after its first discovery in Saccharomyces cerevisiae (7), has now been found in many other yeast genera (2). Production of killer toxin and immunity towards it, is determined by cytoplasmically inherited double stranded RNA (ds RNA) plasmid, linear DNA plasmid or chromosomal elements (22). The killer phenomenon of yeast

*Corresponding Author. Mailing address: Department of Biotechnology, University of Jammu, Jammu-186 001, India.; Tel: +91-94191-02201.; E-mail: bkbajaj1@ rediffmail.com 
may have technological implications in many areas namely beverage fermentation, food technology, biological control in agriculture, and in medicine $(8,22)$. Ecological studies indicate that killer phenomenon confers a competitive edge to the producer strain by excluding other yeasts from its habitat (35).

Attempts have been made in many laboratories all over the world to construct starter cultures with killer character by using variety of techniques like traditional breeding, protoplast fusion, electrofusion or recombinant DNA technology $(11,17$, 26-28, 30). Majority of industrial yeast strains being polyploids of undefined ploidy, are not easily amenable to genetic manipulations, therefore, alternate techniques are employed (2). Most of the studies have been confined to the development of winery and brewery yeasts with killer character. To our knowledge no work is reported regarding the development of distillery yeasts with killer character.

In our previous study, we have shown that incidence of killer yeast in molasses, one of the most commonly used substrates in distilleries, is considerably high; besides, analysis of 21 industrial yeast strains (including $S$. cerevisiae HAU-1, which is being used in several ethanol based fermentation industries in India), showed that all of them were of sensitive phenotype (2). This was perturbing, and we were prompted to consider that it is necessary to develop a starter yeast strain with killer character so that it can destroy the wild contaminating yeasts during ethanol fermentation, and at the same time itself must remain resistant to the wild killer yeasts. The frequent failures of alcoholic fermentation may be due to the action of contaminating wild killer yeasts on the starter cultures, besides other reasons. Considering that ethanol fermentation is conducted in partly sterilized conditions, molasses being contaminated with wild killer yeasts, and sensitive nature of most of the industrial strains, the present study was planned to transfer the killer character into commercial fast (molasses) fermenting distillery yeast strain $S$. cerevisiae HAU-1, by protoplast fusion, and to assess the fermentation performance of the constructed killer yeast with regard to desired ethanol production characteristics, and its ability to deal with wild contaminants from molasses.

\section{MATERIALS AND METHODS}

\section{Organisms, chemicals and media}

Yeast strains used in this study were: Saccharomyces cerevisiae MTCC 475 (reference killer strain) and S. cerevisiae MTCC 473 (reference sensitive strain), procured from Microbial Type Culture Collection and Gene Bank, Institute of Microbial Technology, Chandigarh; distillery yeast $S$. cerevisiae HAU-1 and S. cerevisiae neu (a neutral isolate from molasses), obtained from culture collection of Department of Microbiology, CCS Harayana Agric. University, Hisar. All the yeast strains were maintained on YEPD agar at $4^{\circ} \mathrm{C}$. Chemicals and media components were procured from companies like Difco, Sigma, HI-Media, E-Merck, and Ranbaxy. $\beta$ glucuronidase (Helix pomatia) was obtained from E-Merck (India) Limited.

\section{Introduction/selection of markers in yeast strains}

The two yeast strains, S. cerevisiae MTCC 475 (standard killer strain) and S. cerevisiae HAU-1 (industrial strain), to be used in the protoplast fusion, were marked appropriately for characteristics like resistance/sensitivity to copper sulphate, respiratory deficiency/competence and killer/sensitive phenotype. Copper sulphate resistance $\left(\mathrm{Cup}^{\mathrm{R}}\right)$ or sensitivity $\left(\mathrm{Cup}^{\mathrm{S}}\right)$ of yeast strains was tested by determining their ability to grow in YEPD containing different concentrations of copper sulphate ranging from $0.01 \%$ to $2.5 \%(\mathrm{w} / \mathrm{v})$. Mutation for respiratory deficiency $\left(\rho^{-}\right)$was introduced in $S$. cerevisiae HAU-1 as described earlier (5). S. cerevisiae MTCC 475, standard killer strain was marked as: $\mathrm{K}^{+}$(killer), $\rho^{+}$(respiratory competent), $\operatorname{Cup}^{\mathrm{S}}$ (sensitive to copper sulphate); and $S$. cerevisiae HAU-1, industrial strain was marked as: $\mathrm{K}^{-}$(sensitive), $\rho^{-}$(respiratory deficient), $\operatorname{Cup}^{\mathrm{R}}$ (resistant to copper sulphate), before the two strains were subjected to protoplasting and subsequent fusion. 


\section{Assay of killer activity}

The yeast strains to be tested for killer character were inoculated as streaks of 10-12 mm length on to the surface of the killer assay medium plates pre-seeded with approximately $10^{5}$ cells $\mathrm{ml}^{-1}$ of sensitive yeast strain, S. cerevisiae MTCC 473 (2). Appearance of growth inhibition zone encircled by blue margins representing killed cells, around the streak indicated killer activity, after 24-48 $\mathrm{h}$ of incubation at $30^{\circ} \mathrm{C}$. Quantification of killer activity was carried out by filtering the fermented broth through cellulose acetate filters (Millipore, $0.45 \mu \mathrm{m}$ pore size) and crude cell free toxin preparation obtained was poured (at $70 \mu \mathrm{l} /$ well) in wells of $6 \mathrm{~mm}$ diameter cut in killer assay medium plates pre-seeded with sensitive yeast strain, S. cerevisiae MTCC 473. After diffusion of toxin fluid, plates were incubated at $30^{\circ} \mathrm{C}$ for $48 \mathrm{~h}$. Zones of inhibition surrounded by blue margins of killed cells appeared on the plates were measured.

\section{Protoplast preparation and fusion}

For protoplasts preparation, mid log phase cells grown in YEPD were harvested and washed three times with sterilized distilled water and suspended in protoplasting solution (32), which consisted of, sorbitol (1.2 M) and $\beta$-mercaptoethanol (10 $\mathrm{mM})$ in citrate- phosphate buffer (0.1 M, pH 4.0), and $100 \mu \mathrm{l}$ of $\beta$-glucuronidase (Helix pomatia). The mixture was incubated in water bath at $30^{\circ} \mathrm{C}$ with occasional shaking, and protoplast formation was monitored microscopically, and by exposure to hypotonic environment. When more than $90 \%$ of the cells were converted to protoplasts, suspension was subjected to centrifugation (200 rpm for $10 \mathrm{~min}$ ). Protoplasts were washed thrice with osmotically stabilized protoplasting buffer (citrate-phosphate buffer, $0.1 \mathrm{M}, \mathrm{pH}$ 4.0, containing sorbitol, $1.2 \mathrm{M}$ ) and stored in the same buffer at $4^{\circ} \mathrm{C}$ for further use.

For protoplast fusion, protoplasts of both the yeast strains (approx. $10^{8}$ protoplasts $\mathrm{ml}^{-1}$ of each), S. cerevisiae HAU-1 and S. cerevisiae MTCC 475 (killer), were mixed and suspended in protoplast fusion solution (10), which was composed of polyethylene glycol $(35 \% \mathrm{w} / \mathrm{v})$, calcium chloride
$(10 \mathrm{mM})$ and sorbitol $(1.2 \mathrm{M})$ in citrate-phosphate buffer $(0.1$ $\mathrm{M}, \mathrm{pH}$ 4.0). The contents were incubated for $30 \mathrm{~min}$ in water bath set at $30^{\circ} \mathrm{C}$. Then, the mixture was washed with protoplasting buffer and suspended in $2.0 \mathrm{ml}$ of same buffer. A $0.5 \mathrm{ml}$ of the above suspension was mixed with $4.5 \mathrm{ml}$ of molten, hypertonic, selective regeneration medium (glycerol agar containing copper sulphate, $0.15 \%$, w/v, and sorbitol 1.2 M) and this suspension was poured in plates containing bottom layer of agar of same composition. Plates were incubated at $30^{\circ} \mathrm{C}$ for regeneration of the fusants. The medium was selective in the respect that it can support growth of only fusants and not any of the parents, as glycerol is the sole carbon source it would not support the growth of $\rho^{-}$(respiratory deficient) industrial strain HAU-1, and presence of copper sulphate would inhibit the standard killer strain. However, fusants, which are supposed to possess both the selective characteristics i.e. respiratory competence and resistance to copper sulphate, would grow to form colonies.

\section{Fermentation studies}

Ethanol fermentation studies were carried out as described previously (4). Inoculum was developed in YEPD at $\mathrm{pH} 5.5$ containing 6\% dextrose or molasses (approximately 6\% sugars) under shaking conditions $(200 \mathrm{rpm})$ at $30^{\circ} \mathrm{C}$, and $\log$ phase biomass was inoculated (at $0.75 \%$, w/v) into fermentation medium which consisted of YEPD (pH 5.5) with $16 \%$ dextrose or molasses containing approximately 16\% sugars. Molasses based fermentation medium was supplemented with urea $(0.3 \%, \mathrm{w} / \mathrm{v})$ and disodium hydrogen phosphate $(0.15 \%$, w/v). Fermentation was allowed to proceed under stationary conditions at $30^{\circ} \mathrm{C}$ and samples were withdrawn periodically and analysed for ethanol content spectrophotometrically (9).

\section{Stability of killer character in fusants}

For determining stability of killer character in fusants, samples drawn from fermented broth were appropriately diluted and spread plated on the killer assay medium plates preseeded with sensitive cells, and killer activity was determined for more than 5000 clones. Quantification of killer activity was 
also carried out by using cell free filtrate of fermentation broth as described above in heading assay of killer activity.

\section{Ethanol tolerance of fusants}

Ethanol tolerance of yeast strains was determined spectrophotometrically by measuring the growth in presence of exogenously added ethanol using the following equation:

Total growth $=\mathrm{X}_{\max }-\mathrm{X}_{0}$

$\mathrm{X}_{\max }=$ Maximum growth at particular time, and $\mathrm{X}_{0}=$ Growth at ' 0 ' time

\section{Enzyme assay}

Enzymes assayed in cell free extracts of yeast strains were: invertase (12), pyruvate decarboxylase (25) and alcohol dehydrogenase (6). One unit of invertase activity corresponds to the liberation of one micromole of D-glucose per min. One unit of pyruvate decarboxylase activity was defined as the amount of the enzyme required to produce two micromoles of ferrocyanide per $h$. One unit of alcohol dehydrogenase was defined as one micromole of $\mathrm{NAD}^{+}$reduced per min. Protein content was determined by using bovine serum albumin as standard (21).

\section{RESULTS AND DISCUSSION}

\section{Assessment of fermentation characteristics of parent strains and fusants}

A total of 150 fusants were picked up from selective agar medium based upon colony size and shape. All the picked up fusants were tested for their killer activity against standard sensitive strain, and of these, 81 fusants showed killer activity just like the parent killer strain, and these fusant clones were further tested for their ethanol producing ability in YEPD. Only 4 fusants $\left(F_{3}, F_{38}, F_{81}, F_{121}\right)$ out of total 81 examined, gave an ethanol yield that was comparable to that by the parent industrial strain S. cerevisiae HAU-1 (4). As ethanol producing ability is governed by large number of genes, during protoplast fusion some of these genes might have altered, therefore, many of the fusants yielded much less ethanol content than the parent industrial strain $S$. cerevisiae HAU-1. In further experiments, these 4 fusants having primarily required properties from both the parent strains, were characterized for other desirable fermentation characteristics. Ethanol yield by selected four fusants from molasses, as substrate, was quite satisfactory and comparable with that by industrial strain $S$. cerevisiae HAU-1 (Table 1).

Table 1. Ethanol production by parent strains of Saccharomyces cerevisiae and fusants from dextrose and molasses

\begin{tabular}{lcccc}
\hline Yeast strains & \multicolumn{4}{c}{ Ethanol (\%, v/v) } \\
& Dextrose & \multicolumn{4}{c}{ Molasses } \\
\cline { 2 - 5 } & \multicolumn{4}{c}{ Time (h) } \\
& $\mathbf{2 4}$ & $\mathbf{4 8}$ & $\mathbf{2 4}$ & $\mathbf{4 8}$ \\
\cline { 2 - 5 } & & & & \\
S. cerevisiae HAU-1 & 7.5 & 7.8 & 7.4 & 7.5 \\
S. cerevisiae MTCC 475 & 4.9 & 5.3 & 3.8 & 4.2 \\
$\mathrm{~F}_{3}$ & 7.5 & 7.8 & 7.4 & 7.5 \\
$\mathrm{~F}_{38}$ & 7.5 & 7.8 & 7.4 & 7.5 \\
$\mathrm{~F}_{81}$ & 7.6 & 7.8 & 7.4 & 7.5 \\
$\mathrm{~F}_{121}$ & 7.5 & 7.8 & 7.3 & 7.5 \\
\hline
\end{tabular}

Due to low cost and high nutritional value, molasses is considered as substrate of choice for ethanol production industries but it contains inhibitory substances for yeast growth and fermentation, and many strains either do not ferment or poorly ferment it (31), which sometimes necessitates the pretreatment of molasses to remove the impurities (34) but that always results in cost-shoot up. Therefore, it is highly desirable that an industrial strain must be a good fermenter of raw molasses. In the present investigation, the newly constructed killer yeast $S$. cerevisiae HAU-1 retained the ability to efficiently ferment molasses, and produced ethanol yield that was comparable to that from dextrose (Table 1). Similar reports have been published where in killer hybrids obtained by protoplast fusion possessed other desirable fermentation properties like high ethanol yield from molasses and flocculence, and further more, it was reported that a few of the hybrids yielded even more ethanol than the parent strain (17). In contrast, a newly constructed killer brewing yeast showed 
effective killing properties but very poor brewing characteristics, and the product was more vulnerable to spoilage by killer-resistant wild yeast (16).

The two key enzymes which have got instrumental role in determining the rate and amount of ethanol produced by yeast are pyruvate decarboxylase and alcohol dehydrogenase; and invertase is essential for ethanol production from molasses, and may serve as one of the limiting factors in ethanol production from molasses (31). In the present study, close resemblance in the specific activity of these enzymes was observed in constructed fusants and in industrial strain $S$. cerevisiae HAU-1 (Table 2), which indicates that there has been no or least if any, disturbance in nuclear genes during the process of protoplast fusion, but only cytoplasmic fusion has occurred (11).

Table 2. Specific activity of invertase, alcohol dehydrogenase $(\mathrm{ADH})$ and pyruvate decarboxylase (PDC) in parent strains of S. cerevisiae and in fusants

\begin{tabular}{lccc}
\hline Yeast strains & \multicolumn{3}{c}{ Specific activity (U/mg protein) } \\
\cline { 2 - 4 } & Invertase & ADH & PDC \\
\cline { 2 - 4 } & & & \\
S. cerevisiae HAU-1 & 2.39 & 32.01 & 0.68 \\
S. cerevisiae MTCC 475 & 1.87 & 19.12 & 0.56 \\
$\mathrm{~F}_{3}$ & 2.33 & 31.39 & 0.67 \\
$\mathrm{~F}_{38}$ & 2.29 & 29.95 & 0.60 \\
$\mathrm{~F}_{81}$ & 2.21 & 31.22 & 0.66 \\
$\mathrm{~F}_{121}$ & 2.42 & 32.33 & 0.64 \\
\hline
\end{tabular}

In industrial strains of $S$. cerevisiae desirable ethanol production characteristics namely, fermentation rate, ethanol tolerance, thermotolerance, osmotolerance etc., are determined by a large number of genes, if there is alteration in the nuclear genome during the process of protoplast fusion, there is possibility that some of the desirable features may be lost (11). In contrast, genetically improved yeast developed by protoplast fusion showed higher pyruvate decarboxylase and alcohol dehydrogenacase activity, and produced more ethanol as compared to the parent strains (17). However, cloning and over expression of 8 different enzymes of glycolysis including pyruvate decarboxylase and alcohol dehydrogenase has been reported to cause no improvement in ethanol productivity (24). The results in the present study showed that the activity of key enzymes i.e. pyruvate decarboxylase, alcohol dehydrogenase and invertase, involved in ethanol production was unaltered in the selected 4 fusants (Table 2) and further more, other technological characteristics associated with industrial yeast $S$. cerevisiae HAU-1 like ethanol tolerance (Table 3), ability to perform under biomass recycling and at high sugar concentrations (data not shown) etc. were also maintained in the selected fusants. This substantiates the hypothesis that most of the nuclear genes remain unaltered during protoplast fusion.

The selected 4 fusants were capable of tolerating ethanol up to $10 \%$ (v/v), again resembling the parent industrial strain $S$. cerevisiae HAU-1 (Table 3). Ethanol is inhibitory for microbial growth, and Saccharomyces sp. is believed to be the maximum ethanol tolerant organism. Ethanol producing ability of yeast reflects its intrinsic ability to tolerate ethanol. Sake yeast which produces wines of $20 \%$ ethanol is much more tolerant than brewer's yeast which produces beers of $4-5 \%$ ethanol (3). Ethanol inhibition is directly linked to the denaturation and inhibition of glycolytic/fermentative enzymes and modification of cell membrane. Membrane lipid composition is most drastically effected by exposure of $S$. cerevisiae to ethanol (1). Over expression of OLE 1 in $S$. cerevisiae lead to increased unsaturated fatty acid contents in the recombinant strains, which lead to the enhanced ethanol tolerance of the organism and consequent improved growth and ethanol producing ability (18). In another study, killer yeast developed by electrofusion showed ethanol resistance and osmotolerance like the parent strain but produced high ethanol (26).

Killer character has been introduced in the industrial strains by variety of methods by different researchers $(11,17$, 23, 26, 27, 28, 30). Killer wine yeasts constructed by protoplast fusion not only retained all the technologically important characteristics $(11,26,30)$ but showed potentially more competitive edge against wild yeasts and produced more ethanol than the parent industrial strain (11). 
Table 3. Ethanol tolerance of parent strains of $S$. cerevisiae and fusants

\begin{tabular}{|c|c|c|c|c|c|c|c|}
\hline \multirow[t]{3}{*}{ Yeast strains } & \multicolumn{7}{|c|}{ Growth (Absorbance at $540 \mathrm{~nm}$ ) } \\
\hline & \multicolumn{7}{|c|}{ Ethanol $(\%, \mathrm{v} / \mathrm{v})$} \\
\hline & $\mathbf{0}$ & 2 & 4 & 6 & 8 & 10 & 12 \\
\hline S. cerevisiae HAU-1 & 3.11 & 2.94 & 2.84 & 2.63 & 2.12 & 0.86 & 0.07 \\
\hline S. cerevisiae MTCC 475 & 2.76 & 2.66 & 2.54 & 2.00 & 0.78 & 0.05 & 0.02 \\
\hline $\mathrm{F}_{3}$ & 3.10 & 2.96 & 2.84 & 2.67 & 2.13 & 0.85 & 0.06 \\
\hline $\mathrm{F}_{38}$ & 2.91 & 2.80 & 2.68 & 2.49 & 1.78 & 0.79 & 0.03 \\
\hline $\mathrm{F}_{81}$ & 3.11 & 2.94 & 2.83 & 2.65 & 2.12 & 0.85 & 0.06 \\
\hline $\mathrm{F}_{121}$ & 3.11 & 2.98 & 2.84 & 2.64 & 2.11 & 0.84 & 0.03 \\
\hline
\end{tabular}

Stability of killer character and killer activity of fusants during fermentation

To determine effect of hostile cultural and environmental conditions during industrial fermentation of ethanol, on killer activity of fusants, fusants clones were subjected to batch fermentation in YEPD as well as in molasses medium for 72$96 \mathrm{~h}$, and more than 5000 clones were plated on killer assay medium pre-seeded with sensitive yeast cells. It was found that killer activity was stably maintained during fermentation conditions as all the clones showed killer activity. Further, quantitative measurements of killer activity showed that it remained unaffected under fermentation conditions as indicated by size of inhibition zone (Table 4).

Table 4. Stability of killer activity of fusants during ethanol fermentation

\begin{tabular}{lcc}
\hline Yeast strains & \multicolumn{2}{c}{ Killer activity } \\
\cline { 2 - 3 } & Qualitative & Quantitative \\
& $(>\mathbf{5 0 0 0}$ clones $)$ & Inhibition Zone $(\mathbf{m m})$ \\
& & \\
$\mathrm{F}_{3}$ & + & 20.7 \\
$\mathrm{~F}_{38}$ & + & 21.0 \\
$\mathrm{~F}_{81}$ & + & 20.6 \\
$\mathrm{~F}_{121}$ & + & 20.9 \\
\hline
\end{tabular}

Similar results have been reported elsewhere where a constructed industrial yeast with killer character was reported to remain stable for years of continued application at industrial level (26). However, there are reports indicating much less stability of killer character in hybrids then in the parent killer strains $(16,30)$, such killer hybrids retain killer character for a few series of sub-cultivations under laboratory conditions, and during grape must fermentation, and thereafter killing activity declines and at the end it is minimal or none. However, for successful industrial applications, killer activity of hybrids must be stably maintained, and should be sufficient to combat any possible contamination during at least, for a first few days of grape must fermentation.

\section{Effect of biomass recycling on killer activity}

Biomass recycling is practiced in many ethanol fermentation units mainly to enhance the ethanol yield, besides, it helps saving time, cost and labor, and can play very important role in improving the overall process economy (31). There is a possibility that recycling of biomass may lead to the loss of killer character. Fermentation was run by using the constructed fusant strain in YEPD as well as in molasses medium for fifteen cycles of $24 \mathrm{~h}$ each, by inoculating the biomass collected at the end of each cycle into the next batch. It was found that killer activity was maintained as vigorously as it was in the first batch, after fifteen cycles as indicated by the results obtained by spreading the cells from fermented broth on killer assay medium plates pre-inoculated with sensitive cells. Further, quantitative measurement of the killer activity also endorsed that killer activity remained unfazed during the harsh conditions of biomass recycling during 
ethanol fermentation. This indicates stable maintenance of killer character even under hostile distillery conditions of biomass recycling. Biomass recycling puts considerable stress on the fermenting organism and the organism tends to be genetically unstable (5).

\section{Effect of pH and temperature on killer activity}

Since killer toxin is a protein/glycoprotein, it may loose its activity when exposed to extremes of $\mathrm{pH}$ and temperature. Killer activity was tested after running fermentation in media with different $\mathrm{pH}$ (3.0-6.0). It was found that killer activity was expressed maximally in $\mathrm{pH}$ range of 4.0 to 5.5 , as indicated by the size of inhibition zone $(21 \mathrm{~mm}) ; \mathrm{pH}$ above and below this range caused decrease of killer activity (Table 5). Similarly, the effect of temperature on killer activity of fusants was determined by carrying out fermentation at different temperatures $\left(20-45^{\circ} \mathrm{C}\right)$. Killer activity was maintained at its maximum in the range of $20-35^{\circ} \mathrm{C}$ and it decreased with further rise in temperature and totally lost at $45^{\circ} \mathrm{C}$ (Table 6).
Temperature and $\mathrm{pH}$ optima for maximum killer activity were comparable in standard killer strain, S. cerevisiae MTCC 475 and in constructed fusants. Optimum $\mathrm{pH}$ for killer activity has been defined for a number of killer toxins, with the majority of them having an optimum $\mathrm{pH}$ between 4.1 and $4.7(15,29)$. The first step of adsorption of killer toxin to the cell wall receptor $\beta$-(1-6)-D-glucan, is strongly $\mathrm{pH}$ dependent and optimum $\mathrm{pH}$ for this is 4.6 (20). Similar results have been documented by others $(14,35)$. Majority of killer toxins lose activity above $25^{\circ} \mathrm{C}(15,29)$ but killer toxin from Williopsis saturns var. mrakii IFO0895 exhibited exceptional temperature and $\mathrm{pH}$ stability that was probably due to presence of many disulphide bonds in cysteine rich toxin (19). The differential stability of killer toxins from different yeasts is mainly due to variations in their physico-chemical properties with respect to amino acid composition and structure (35). Also, these variations also accounts for differential mechanism of action of killer toxins from different yeasts.

Table 5. Effect of $\mathrm{pH}$ on killer activity of yeast $S$. cerevisiae MTCC 475 and fusants

\begin{tabular}{|c|c|c|c|c|c|c|c|}
\hline \multirow[t]{3}{*}{ Yeast strains } & \multicolumn{7}{|c|}{ Inhibition Zone (mm) } \\
\hline & \multicolumn{6}{|c|}{ pH } & \multirow[b]{2}{*}{6.0} \\
\hline & 3.0 & 3.5 & 4.0 & 4.5 & 5.0 & 5.5 & \\
\hline S. cerevisiae MTCC 475 & 12.4 & 16.5 & 20.9 & 21.0 & 21.0 & 21.0 & 13.9 \\
\hline $\mathrm{F}_{3}$ & 11.5 & 14.7 & 21.0 & 21.1 & 21.0 & 21.0 & 13.1 \\
\hline $\mathrm{F}_{38}$ & 11.1 & 15.6 & 20.6 & 20.8 & 20.9 & 20.7 & 11.3 \\
\hline $\mathrm{F}_{81}$ & 12.3 & 16.6 & 21.0 & 21.0 & 20.6 & 20.9 & 12.3 \\
\hline $\mathrm{F}_{121}$ & 11.9 & 16.6 & 20.7 & 20.7 & 20.9 & 21.0 & 12.8 \\
\hline
\end{tabular}

Table 6. Effect of temperature on killer activity of yeast $S$. cerevisiae MTCC 475 and fusants

\begin{tabular}{|c|c|c|c|c|c|c|c|}
\hline \multirow[t]{3}{*}{ Yeast strains } & \multicolumn{7}{|c|}{ Inhibition Zone (mm) } \\
\hline & \multicolumn{6}{|c|}{ Temperature $\left({ }^{\circ} \mathrm{C}\right)$} & \multirow[b]{2}{*}{45} \\
\hline & 15 & 20 & 25 & 30 & 35 & 40 & \\
\hline S. cerevisiae MTCC 475 & 17.7 & 21.0 & 21.0 & 21.0 & 20.7 & 13.5 & - \\
\hline $\mathrm{F}_{3}$ & 18.1 & 20.3 & 21.0 & 21.0 & 21.0 & 12.8 & - \\
\hline $\mathrm{F}_{38}$ & 16.9 & 20.9 & 20.8 & 21.0 & 20.7 & 11.0 & - \\
\hline $\mathrm{F}_{81}$ & 17.5 & 21.0 & 21.0 & 21.0 & 21.0 & 14.1 & - \\
\hline $\mathrm{F}_{121}$ & 16.8 & 21.0 & 21.0 & 20.9 & 20.6 & 11.5 & - \\
\hline
\end{tabular}




\section{Killer action of fusants against Saccharomyces and non- saccharomyces contaminants from molasses}

The constructed killer yeast can be worthwhile if it is capable of killing all types of wild yeast contaminants commonly found in molasses like Saccharomyces, Schizosaccharomyces Kluyveromyces, Hansenula, Kloeckera, Pichia, Torulopsis etc. (2). However, in the present study, the killer action of constructed killer yeast was not detected against any of the non-saccharomyces wild yeast contaminants from molasses. But the constructed fusants as well as the parent reference killer strain MTCC 475 successfully killed all the Saccharomyces sp. isolates from molasses (data not shown). Ideally, the industrial starter culture must show broad range killing ability against wild contaminants.

\section{Conclusions}

In this study, killer character has been successfully transferred into industrial yeast $S$. cerevisiae HAU-1 by protoplast fusion. Examination of 4 fusants showed that all the desirable fermentation properties of distillery strain $S$. cerevisiae HAU-1 are substantially retained, sustaining the hypothesis that nuclear DNA exchanges if any, had been minimal. Further, it is realized that there is a need to develop a distillery strain of $S$. cerevisiae with a broad spectrum of killer activity, which should be practically active against all types of wild yeasts, Saccharomyces as well as non-saccharomyces spp. present in molasses and other substrates.

\section{ACKNOWLEDGEMENTS}

Dr. B.K. Bajaj gratefully acknowledges Council of Scientific and Industrial Research (CSIR), and University Grant Commission (UGC), Govt. of India, for providing the financial assistance for conducting this research.

\section{REFERENCES}

1. Arenborg, N.; Hoy, C.E.; Jorgensen, O.B. (1995). The effect of ethanol and specific growth rate on the lipid content and composition of Saccharomyces cerevisiae grown anaerobically in the chemostat. Yeast
11, 953-959.

2. Bajaj, B.K.; Dilbaghi, N.; Sharma, S. (2003). Incidence of killer yeast in molasses and status of industrial yeast with respect to killer character. $J$. Sci. Industrial Res. 62, 714-717.

3. Bajaj, B.K.; Sheema, Y.; Thakur, R.L. (2001). Selection and characterization of yeasts for desirable fermentation characteristics. Indian J. Microbiol. 41, 107-110.

4. Bajaj, B.K.; Taank, V.; Thakur, R.L. (2005). Potential industrial applications of yeast capable of fermenting high gravity cane molasses despite physiological stress. Indian J. Biotechnol. 4, 149-152.

5. Bajaj, B.K.; Tauro, P. (1994). Respiratory instability in distillery yeast. Biotechnol. Lett. 16, 631-636.

6. Barron, E.S.G.; Levine, S. (1952). Oxidation of alcohol by yeast alcohol dehydrogenase and by the living cell. The thiol groups of the enzyme. Arch. Biochem. Biophy. 41, 175-187.

7. Bevan, E.A; Makower, M. (1963). The physiological basis of the killer character in yeast. Proceeding of the 11th International Conference on Genetics 1, 203.

8. Cabral A.S.; Carvalho, P.M. B; Pinotti, T.; Hagler, A.N.; MendonçaHagler, L.C.S.; Macrae, A. (2009). Killer yeasts inhibit the growth of the phytopathogen Moniliophthora perniciosa, the causal agent of Witches' Broom disease. Braz. J. Microbiol. 40, 108-110.

9. Caputi, A.; Ueda, J.M.; Brown, T. (1968). Spectrophotometric determination of chromic complex formed during oxidation of alcohol. Am. J. Enol. Viticult. 19, 160-165.

10. Farahnak, F.T.; Seki, D.D.; Rya, Y.; Ogrydziak, D. (1986). Construction of lactose assimilating and high ethanol producing yeast by protoplast fusion. Appl. Environ. Microbiol. 51, 362.

11. Farris, G.A.; Fatichenti, F.; Bifulco, I.; Berordi, E.; Deiana, P.; Satta, T. (1992). A genetically improved wine yeast. Biotechnol. Lett. 14, 219222.

12. Gas'con, S.; Lampen, J.O. (1968). Purification of the internal invertase of yeast. J. Biol. Chem. 243, 1567-1572.

13. Gnansounou, E; Dauriat, A. (2005). Ethanol fuel from biomass: A review. J. Sci. Industrial Res. 64, 809-822.

14. Goto, K.; Iwase, T.; Kichise, K.; Kitano, K., Totuka, A., Obata, T., Hara, S. (1991). Isolation and properties of a chromosome dependent KHR killer toxin in Saccharomyces cerevisiae. Agric. Biol. Chem. 54, 505509.

15. Heard, G.M.; Fleet, G.H. (1987). Occurrence and growth of killer yeasts during wine fermentation. Appl. Environ. Microbiol. 13, 2171-2174.

16. Hinrichs, J.; Holz, C.; Evers, H.; Wackerbaver, K.; Stall, U. (1994). Brewers yeast cultures with protection against contamination. Brauwelt 134, 113-114.

17. Javadekar, V.S.; Sivaraman, H.; Gokhale, D.V. (1995). Industrial yeast strain improvement: construction of highly flocculent yeast with a killer character by protoplast fusion. J. Industrial Microbiol. 15, 94-102.

18. Kajiwara, S.; Aritomi, T.; Suga, K.; Ohtaguchi, K.; Kobayashi, O. (2000). Overexpression of the $O L E 1$ gene enhances ethanol fermentation 
by Saccharomyces cerevisiae. Appl. Microbiol. Biotechnol. 53, 568-574.

19. Kimura, T.; Kitamoto, N.; Ohata, Y.; Kito, Y.; Imura, Y. (1995). Structural relationships among killer toxins secreted from the killer strains of the genus Williopsis. J. Ferment. Bioengg. 80, 85-87.

20. Kurzweilova, H.; Sigler, K. (1994). Kinetic studies of killer toxin K1 binding to yeast cells indicate two receptor populations. Arch. Microbiol. 162, 211-214.

21. Lowry, O.H.; Rosinbrough, N.I.; Farr, A.L.; Randall, R.J. (1951). Protein measurement with the folin phenol reagent. J. Biol. Chem. 193, 265-275.

22. Marquina, D.; Santos, A.; Peinado, J.M. (2002). Biology of killer yeasts. Int. Microbiol. 5, 65-71.

23. Michalcakova, S.; Sturdik, E.; Sulo, P. (1997). Construction and properties of K2 and K3 type killer Saccharomyces wine strains. WeinWissenschaft 49, 130-132.

24. Ostergaard, S.; Olsson, L.; Nielsen, J. (2000). Metabolic engineering of Saccharomyces cerevisiae. Microbiol. Mol. Biol. Rev. 64, 34-50.

25. Reed, L.J.; Williams, C.R. (1966). Purification and resolution of pyruvate dehydrogensae complex (E. coli). Methods Enzymol. 9, 258261.

26. Salek, A.T.; Arnold, W.M. (1994). Construction of ethanol-resistant, osmophillic industrial strains of Saccharomyces sp. Chem. Mikrobiol. Technol. 16, 165-183.

27. Schmitt, M.J.; Schernikau, G. (1997). Construction of cDNA based $k_{1}$ / $\mathrm{k}_{2} / \mathrm{k}_{28}$ triple killer strain of Saccharomyces cerevisiae. Food Technol. Biotechnol. 35, 281-285.

28. Seki, T.; Chol, E.H.; Ryu, D. (1985). Construction of killer wine yeast strain. Appl. Environ. Microbiol. 49, 1211-1215.

29. Soares, G.A.M.; Sato, H.H. (2000). Characterization of the Saccharomyces cerevisiae Y500-4L killer toxin. Braz. J. Microbiol. 31, 291-297.

30. Sulo, P.; Michalcakova, S.; Reiser, V. (1992). Construction and properties of K1 type killer wine yeasts. Biotechnol. Lett. 14, 55-60.

31. Tauro, P.; Gupta, B.; Yadav, A.; Bajaj, B.K. (1995). Yeast in India: An overview of industry related research. In: Sankaran, R., Manja, K.S. (eds). Microbes for Better Living. Micon- $94^{\text {th }}$ and $35^{\text {th }}$ AMI Conference, DFRL, Mysore, India, p. 521-531.

32. Van Solingen, P.; Platt, V. (1977). Fusion of yeast protoplasts. J. Bacteriol. 130, 946-947.

33. Wyman, C.E. (2007). What is (and is not) vital to advancing cellulosic ethanol. Trends. Biotechnol. 25, 153-157.

34. Yadav, A.; Bajaj, B.K.; Sharma, S. (1998). Effect of pretreatment of molasses in ethanol production by different yeast strains. Environ. Ecol. 16, 579-583.

35. Yap, N.A.; Lopes, M.B.; Langridge, P.; Heschke, P.A. (2000). Incidence of killer activity of non-saccharomyces yeasts towards indigenous yeast species of grape must: potential application in wine fermentation. $J$. Appl. Microbiol. 89, 381-389. 